\title{
BMJ Open Is untargeted iron supplementation harmful when iron deficiency is not the major cause of anaemia? Study protocol for a double-blind, randomised controlled trial among non-pregnant Cambodian women
}

Jordie AJ Fischer (1D ,1,2 Lulu X Pei, , ${ }^{1,2}$ David M Goldfarb, ${ }^{2,3}$ Arianne Albert, ${ }^{4}$ Rajavel Elango, ${ }^{2,5}$ Hou Kroeun, ${ }^{6}$ Crystal D Karakochuk ${ }^{1,2}$

To cite: Fischer JAJ, Pei LX Goldfarb DM, et al. Is untargeted iron supplementation harmful when iron deficiency is not the major cause of anaemia? Study protocol for a doubleblind, randomised controlled trial among non-pregnant Cambodian women. BMJ Open 2020;10:e037232. doi:10.1136/ bmjopen-2020-037232

- Prepublication history and additional material for this paper are available online. To view these files, please visit the journal online (http://dx.doi. org/10.1136/bmjopen-2020037232).

Received 24 January 2020 Revised 29 June 2020 Accepted 02 July 2020
Check for updates

(C) Author(s) (or their employer(s)) 2020. Re-use permitted under CC BY-NC. No commercial re-use. See rights and permissions. Published by BMJ.

For numbered affiliations see end of article.

Correspondence to Dr Crystal D Karakochuk; Crystal.Karakochuk@ubc.ca

\section{ABSTRACT}

Introduction The WHO recommends daily oral iron supplementation for 12 weeks in women and adolescents where anaemia prevalence is greater than $40 \%$. However, if iron deficiency is not a major cause of anaemia, then, at best, untargeted iron supplementation is a waste of resources; at worst, it could cause harm. Further, different forms of iron with varying bioavailability may present greater risks of harm.

Methods and analysis A 12-week three-arm, doubleblind, randomised controlled supplementation trial was conducted in Cambodia to determine if there is potential harm associated with untargeted iron supplementation. We will recruit and randomise 480 non-pregnant women (ages 18-45 years) to receive one of three interventions: $60 \mathrm{mg}$ elemental iron as ferrous sulfate (the standard, commonly used form), $18 \mathrm{mg}$ ferrous bisglycinate (a highly bioavailable iron amino acid chelate) or placebo. We will measure ferritin concentrations (to evaluate non-inferiority between the two forms of iron), as well as markers of potential harm in blood and stool (faecal calprotectin, gut pathogen abundance and DNA damage) at baseline and 12 weeks. Mixed-effects generalised linear models will be used to assess the effect of iron on ferritin concentration and markers of potential harm at 12 weeks.

Ethics and dissemination Ethical approval was obtained from the University of British Columbia Clinical Research Ethics Board (H18-02610), the Children's and Women's Health Centre of British Columbia Research Ethics Board (H18-02610) and the National Ethics Committee for Health Research in Cambodia (273-NECHR). Findings will be published in peer-reviewed journals, presented to stakeholders and policymakers globally and shared within participants' communities.

Trial registration number ClinicalTrials.gov Registry (NCT04017598).

\section{INTRODUCTION}

In 2016, the WHO implemented a global policy recommending daily oral iron
Strengths and limitations of this study

- This trial will be the first to evaluate the potential harm of daily oral iron supplementation in women, in accordance with the 2016 WHO global policy.

- The trial will explore the use of a more bioavailable form of iron (ferrous bisglycinate) as compared with the standard iron salt (ferrous sulfate).

- The study design is a rigorous double-blind, randomised placebo-controlled trial.

- We will comprehensively measure numerous markers of nutrition and inflammation status and genetics in blood, DNA and stool.

- Potential for identification of other adverse outcomes not measured in our supplementation trial which may suggest risk of harm from iron (eg, lipid peroxidation).

supplementation (60 mg iron) for 12 weeks in women and adolescents where anaemia prevalence is greater than $40 \%$, such as in Cambodia. ${ }^{1}$ The WHO policy is based on the assumption that approximately $50 \%$ of anaemia in low-income countries is due to iron deficiency and that iron supplementation has well-established benefits for irondepleted women. ${ }^{2}$ Yet eight recent surveys in non-pregnant women in seven countries reported a surprisingly low prevalence of iron deficiency $(0 \%-8 \%$ based on inflammationadjusted ferritin $<15 \mu \mathrm{g} / \mathrm{L}) .^{3-11}$ If iron deficiency is not a major cause of anaemia, then at best, untargeted iron supplementation is a waste of resources; at worst, it could cause harm.

As such, given the WHO policy and the massive global scope of implementation, there is an urgent need to determine if there 
is harm associated with untargeted iron supplementation. To date, however, most studies of iron supplementation efficacy have failed to assess harms beyond gastrointestinal side effects. This is not adequate, as iron is a catalyst of oxidative and inflammatory reactions. ${ }^{12} 13$ Excess iron can cause oxidative stress, ${ }^{14}{ }^{15}$ DNA and cellular damage ${ }^{15-18}$ and is associated with diabetes, neuropathy and some cancers. ${ }^{19-21}$ Studies in infants and children have shown decreased growth, ${ }^{22}{ }^{23}$ impaired development $^{24-26}$ and increased morbidity. ${ }^{23}{ }^{27-29}$ Excess unabsorbed iron in the colon can also increase susceptibility to pathogen growth. ${ }^{130-32}$ Gut pathogen abundance and gut inflammation were found to be elevated in Kenyan children at doses of iron that are 1/12 (8\%) of the dose currently recommended for women. ${ }^{13} 32$

\section{Iron supplementation in Cambodia}

Over the past decade, Cambodia has adopted numerous policies to combat anaemia through supplementation, yet according to ferritin measurements reported by the 2014 demographic and health survey, only $3 \%$ of Cambodian women had iron deficiency while $45 \%$ of women were anaemic. ${ }^{33}$ In 2015, we conducted an oral iron supplementation trial (12 weeks of $60 \mathrm{mg}$ iron) among 809 predominantly-anaemic women (ages 18-45 years) in Cambodia. We found that iron deficiency was not the cause of anaemia in most of our cohort: $78 \%$ were ironreplete at baseline (ferritin $>15 \mu \mathrm{g} / \mathrm{L}$ ). However, $74 \%$ had a genetic haemoglobinopathy, predominately $\alpha$-thalassemia or haemoglobin E variants. ${ }^{34}$ The potential for iron supplementation to cause harm would be especially significant in women with genetic haemoglobinopathies, as these disorders cause altered iron metabolism and an increased risk of iron overload. ${ }^{35}$

\section{Effects of iron supplementation and the gut microbiota}

Iron is a growth-limiting nutrient, which is essential for numerous gut bacteria competing for unabsorbed dietary iron in the colon. ${ }^{36-38}$ With many enteric gram-negative bacteria, the acquisition of iron plays a vital role in the virulence and colonisation of species such as Shigella, Salmonella and Escherichia coli. 39 40 The beneficial bacteria of the gut provide an important 'barrier effect,' protecting against the colonisation of enteropathogens. ${ }^{41}$ Beneficial commensal bacteria, such as lactobacilli, do not require iron and therefore, do not increase proportionately to the pathogenic bacteria in the presence of iron. ${ }^{42}$ As only some kinds of bacteria use iron, an increase in supplemented iron passing unabsorbed into the colon may modify the colonic microbiota composition, as well as favour growth of pathogenic bacteria over beneficial bacteria. ${ }^{37}$ Changes in the equilibrium of the gut microbiota are observed in conditions involving inflammation of the gut. The inflamed microenvironment is particularly favourable to blooms of enterobacterial species, leading to intestinal harm, which would otherwise be in relatively low abundance. ${ }^{43}$ However, very few studies have investigated the effect of iron supplementation on the dynamics of the gut microbiota nor investigated different iron compounds with varying bioavailability.

Global iron supplementation (both in the absence of iron deficiency and in areas with a high prevalence of haemoglobinopathies) is additionally concerning because the most common form of supplementation, ferrous sulfate, is poorly absorbed. Typically $<20 \%$ of iron is absorbed in the duodenum, and the remaining amount passes unabsorbed into the colon, ${ }^{44}$ which can contribute to the virulence and colonisation of enteropathogens. ${ }^{3639}{ }^{45}$ Ferrous sulfate has also shown to irritate the stomach lining, causing gastrointestinal side effects such as cramping, nausea and constipation, ${ }^{46}$ thus affecting the patient's adherence to iron supplementation treatment and the efficacy of the form of iron. A highly stable iron amino acid chelate, ferrous bisglycinate, has become increasingly popular, as its bioavailability is two to four times greater than 'conventional' iron salts, ${ }^{47-50}$ namely ferrous sulfate, and has been associated with fewer gastrointestinal side effects. ${ }^{51}$ Due to its chemical composition, it does not form insoluble compounds with substances that have a high content of iron absorption inhibitors, such as phytates found in cereal-based foods, ${ }^{49}$ including rice, which makes up a large portion of the Cambodian diet.

To our knowledge, no studies have reported on the relationship between iron supplementation and harm to the gut in non-pregnant women of reproductive age. The effect of iron fortification on gut pathogen abundance has been examined in children. In 139 Ivorian children, iron-fortified biscuits significantly increased the abundance of faecal enterobacteria which correlated with increased levels of faecal calprotectin, a marker of gut inflammation, while lactobacilli abundance decreased. ${ }^{52}$ When the iron-fortified porridge was given to 115 Kenyan infants, modification of the gut microbiome was observed through increased faecal calprotectin and enterobacteria abundance, including Shigella and pathogenic E. coli, and decreased bifidobacteria, shifting towards a more pathogenic gut bacteria profile. ${ }^{13}$ The iron group also had increased faecal calprotectin levels, again indicating intestinal inflammation. ${ }^{13}$ There is some emerging evidence showing that iron fortification in infants and children in developing countries is linked to gut dysbiosis with the enhanced presence of enteropathogens and inflammation. Clearly, there is a lack of high-quality data investigating the potential harms of untargeted iron supplementation in women of reproductive age or ironreplete individuals.

\section{Study aims and outcome measures}

The aims of this study are to (1) assess the non-inferiority of $18 \mathrm{mg}$ iron as ferrous bisglycinate (experimental) as compared with $60 \mathrm{mg}$ iron as ferrous sulfate (standard treatment) on mean ferritin concentrations at 12 weeks and (2) to determine if $60 \mathrm{mg}$ iron as ferrous sulfate (as per the WHO global policy) increases biomarkers of 
potential harm in women at 12 weeks, as compared with placebo or $18 \mathrm{mg}$ iron as ferrous bisglycinate.

We hypothesise that $18 \mathrm{mg}$ ferrous bisglycinate will be as efficacious as $60 \mathrm{mg}$ ferrous sulfate in increasing ferritin concentrations over 12 weeks and that women who receive 12 weeks of $60 \mathrm{mg}$ ferrous sulfate will have increased biomarkers of potential harm, compared with women who received placebo or $18 \mathrm{mg}$ daily oral iron as ferrous bisglycinate.

The primary outcome for the first objective is inflammation-adjusted ${ }^{53}$ mean serum ferritin concentrations $(\mu \mathrm{g} / \mathrm{L})$ at 12 weeks. Iron deficiency will be defined as inflammation-adjusted serum ferritin concentration $<15 \mu \mathrm{g} / \mathrm{L}$, as recommended by the WHO for women of reproductive age ${ }^{53-55}$ The primary outcome for the second objective measuring potential harm is faecal calprotectin concentration ( $\mathrm{mg} / \mathrm{kg}$ stool). The secondary outcome measures for potential harm are gut pathogen abundance, gut parasite abundance and DNA damage. The secondary outcome measures of biochemical status include inflammation markers: 1-acid glycoprotein $($ AGP $(\mathrm{g} / \mathrm{L}))$, C reactive protein $(\mathrm{CRP}(\mathrm{mg} / \mathrm{L}))$; haemoglobin $(\mathrm{g} / \mathrm{L})$, as part of a Complete Blood Count $(\mathrm{CBC})$, including mean corpuscular volume (MCV, fL), mean corpuscular haemoglobin ( $\mathrm{MCH}, \mathrm{pg})$, red cell distribution width (RDW, \%) and reticulocyte count (\% of RBC); folate $(\mathrm{ng} / \mathrm{mL})$, vitamin $\mathrm{B}_{12}$; reported side effects as a quality of life measure and presence of genetic haemoglobin disorders.

\section{METHODS AND ANALYSIS}

\section{Study design and setting}

This is a three-arm, double-blind, randomised placebocontrolled trial among women of reproductive age in Kampong Thom province, Cambodia. The study timeline and schedule for data collection is shown in figure 1 . The study takes place in rural communities involving women living in villages under the following health centres: Prey Kuy, Tboung Krapeu and Srayov. A detailed trial protocol was developed in accordance with the Standard Protocol Items: Recommendations for Interventional Trials guidelines. This study will be conducted in collaboration with Helen Keller International, Cambodia (HKI) (Phnom Penh, Cambodia) and the Cambodian Ministry of Health (Phnom Penh, Cambodia). Funding was obtained from the Canadian Institutes of Health Research.

\section{Participants}

Women who meet the selection criteria and sign the informed consent form after receiving information about the objectives and protocol of the study will be enrolled.

Inclusion criteria: Women aged 18-45 years who are apparently healthy, consent to participate in the study and provide blood, flocked rectal swab and stool samples, and intend to reside in the trial location for the study period.

Exclusion criteria: having any known illness or disease, being pregnant, and taking antibiotics, non-steroidal antiinflammatory drugs, dietary supplements or vitamin and mineral supplements in the previous 12 weeks.

\section{Recruitment}

Experienced local research field staff and phlebotomists will be based in Kampong Thom for the duration of the trial to oversee eligibility screening, recruitment, conduct data and sample collection, tablet distribution, monitoring, reporting and counselling. Chosen study villages will be randomly selected from a list of all villages in the province. Communication about the study will begin with consultations with community village leaders, followed by community sensitisation sessions with local health professionals sharing information and details about the study in the local language (Khmer). The research team will meet with potential participants, screen for eligibility, obtain consent and enrol women. At the initial household visit, women will be informed about the aim, objectives and protocol of the study, as well as eligibility and exclusion criteria. Once written consent (signature) is obtained for both study participation and willingness to provide blood, flocked faecal swab and stool samples, the woman

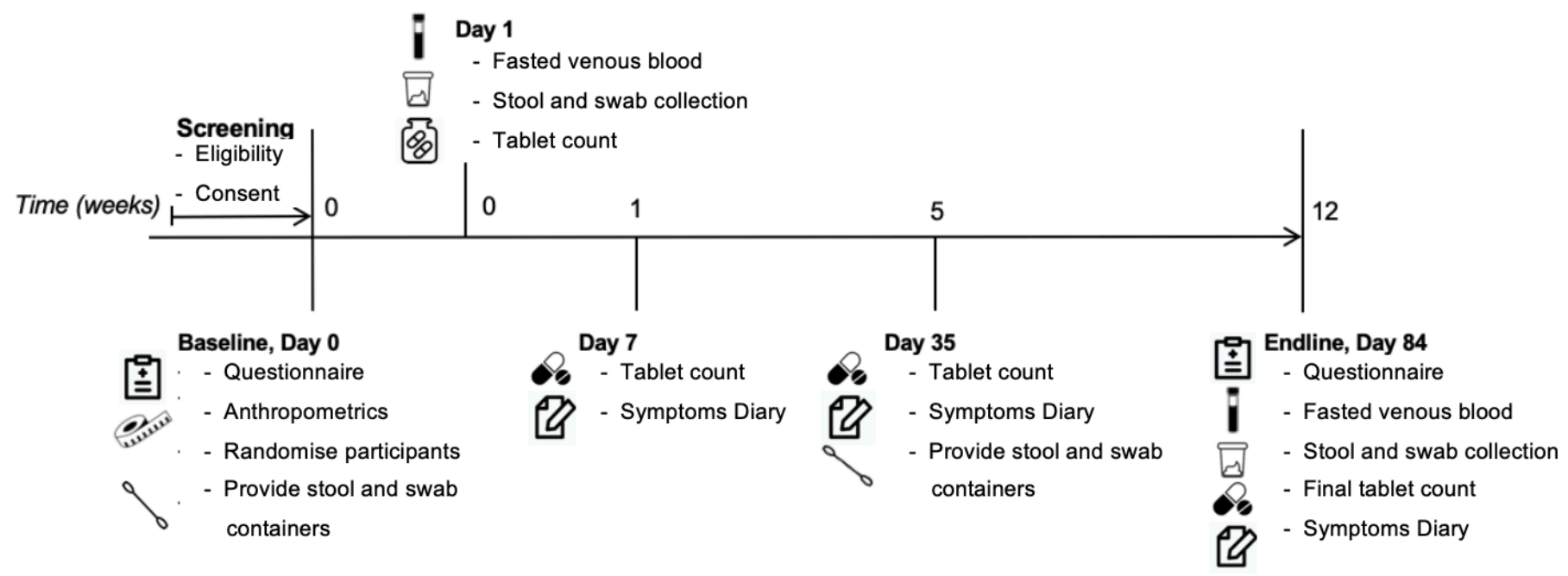

Figure 1 Study timeline and schedule for data collection for iron supplementation trial in Kampong Thom, Cambodia. 
will be enrolled in the study. Recruitment will continue on a rolling basis until 480 women are enrolled. Women will have the opportunity to ask questions, refuse participation in the study and/or withdraw from the study at any time without consequence or question. The reasons for withdrawal will be recorded, and any data collected up until the date of withdrawal will be retained for analysis. Women will be informed at the time of consent that if they become pregnant during the intervention period, they will be removed from the study and provided with an iron and folic acid (as per the current standard of care in Cambodia).

Recruitment commenced in early December 2019 with rolling enrolment. Community sensitisation began with consultations with health centre staff and continued with village chiefs and village health volunteers.

\section{Sample size}

We based our calculation on a non-inferiority comparison between the two iron groups. To detect a non-inferiority margin of $20 \mu \mathrm{g} / \mathrm{L}$ for ferritin, with $80 \%$ power and $\alpha=0.05$, we would require $n=140$ in each group. WHO has reported a clinically important change in ferritin in response to an iron intervention to be $\pm 0.2 \mathrm{SD}$ units. ${ }^{56}$ Data from our 2015 trial indicated the SD of ferritin to be
$50 \mu \mathrm{g} / \mathrm{L}$ after 12 weeks of $60 \mathrm{mg}$ iron; ${ }^{34}$ therefore, a margin of $20 \mu \mathrm{g} / \mathrm{L}$ was chosen. Thus, we require $\mathrm{n}=140 \mathrm{in}$ each of the three groups. Accounting for $15 \%$ loss to follow-up (a conservative estimate based on our previous trial), ${ }^{34}$ we require $n=160$ women in each of the three groups and a total of $n=480$ women in the study (figure 2 ).

\section{Randomisation and blinding}

Women will be randomised at the health centre level with a 1:1:1 allocation ratio to one of the three interventions by a computer-generated random list organised by JF. A total of 480 women will be randomised, with a target of allocating 160 women to each group. A unique identifier will be assigned to each participant. An independent scientist determined which supplement bottle code corresponded to which intervention group. Allocation will be concealed from the trial investigators, research staff and participants to prevent bias. The concealed allocation sequence will be coordinated by an external elected investigator. The allocation codes will remain blinded to the principal investigator and entire research team during all stages of the trial until after the primary outcome has been analysed. Preliminary unblinding of the trial is to be executed only by an independent researcher as deemed necessary in the case of a severe adverse event.

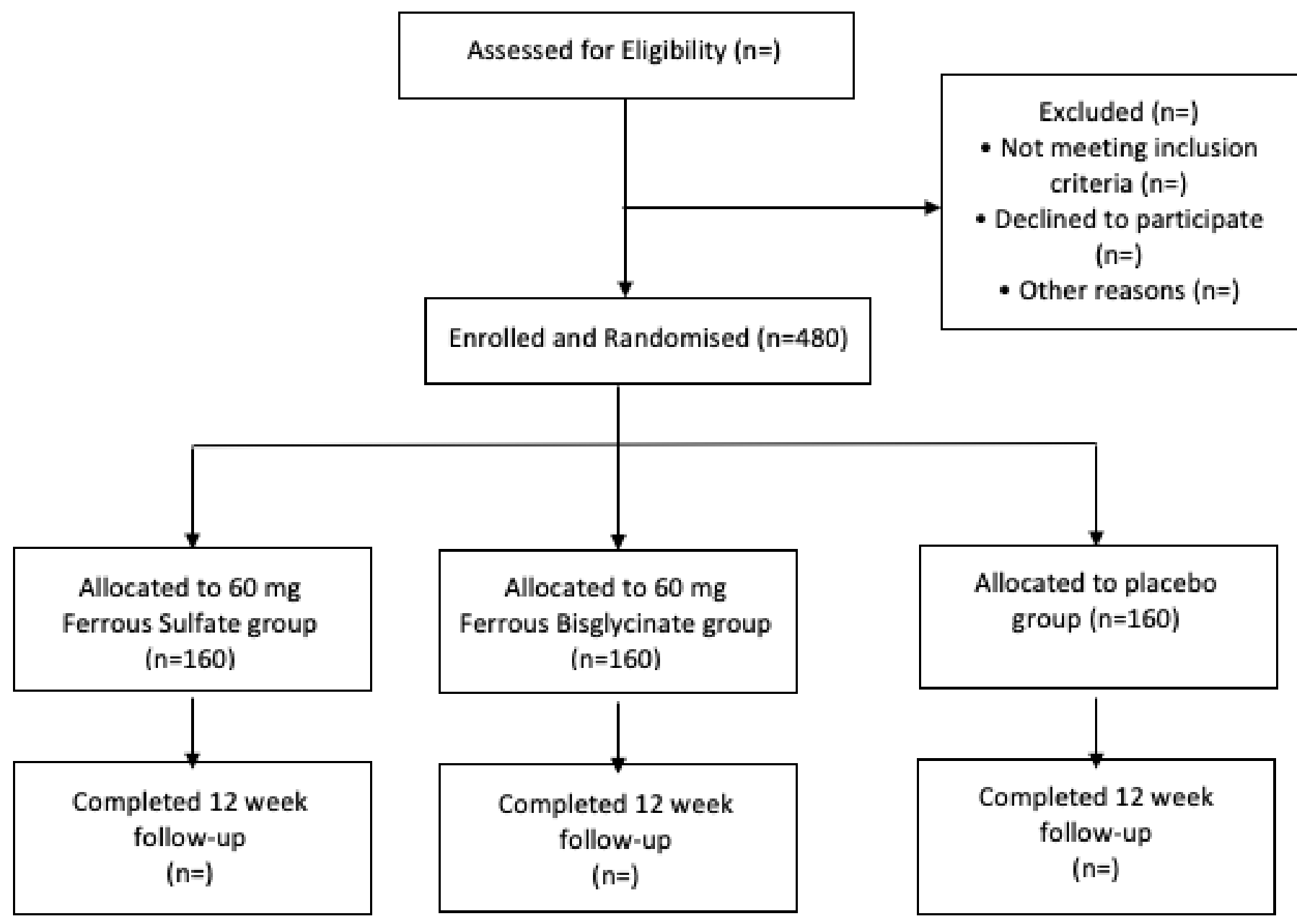

Figure 2 Participation flowchart. 
Table 1 Schedule of assessment time points and study visits

\begin{tabular}{|c|c|c|c|c|c|c|c|}
\hline \multirow[b]{2}{*}{ Visit (V) } & \multicolumn{7}{|c|}{ Assessment time points } \\
\hline & Screening & V1 & V2 & V3 & V4 & V5 & Study end \\
\hline Time per session, hours & & 0.5 & 0.25 & 0.25 & 0.25 & 0.5 & 1 \\
\hline Study week & & 0 & 0 & 1 & 5 & 12 & $12+$ \\
\hline Enrolment and random & & & & & & & \\
\hline
\end{tabular}

Eligibility assessment

Randomisation

$X$

Implementation

Questionnaire

Flocked rectal swab and stool collection kit provided

Blood collection

Flocked rectal swab and stool sample collected

Adverse event reporting

Review symptoms diary

$X$

Supplementation

Tablet distribution

Tablet count

$x$

$\mathrm{X}$

$X$
$X$

$X$

$\begin{array}{ll}x & x \\ x & x\end{array}$

$\begin{array}{lll}x & x \\ x & x\end{array}$

\section{Education}

Nutrition education workshop

\section{Intervention}

Eligible women will be randomised to receive one of three interventions for 12 weeks: $60 \mathrm{mg}$ elemental iron as ferrous sulfate (the standard, commonly used form), $18 \mathrm{mg}$ ferrous bisglycinate (a highly bioavailable iron amino acid chelate) or placebo. The supplements were produced in-kind by The Factors Group of Companies (Coquitlam, Canada). The iron and placebo tablets are, except for the elemental iron content, identical in composition, taste, smell and appearance. Each placebo tablet of microcrystalline cellulose contains no elemental iron. The ferrous sulfate tablet contains $60 \mathrm{mg}$ elemental iron as the WHO global policy is to supplement all women of reproductive age with $60 \mathrm{mg}$ iron for 12 weeks. The ferrous bisglycinate tablet contains $18 \mathrm{mg}$ elemental iron, a dose chosen on account of its greater bioavailability than iron salts and is also the dose commonly sold in Canada. ${ }^{47-50}$

\section{Procedures}

Enrolled women take part in a recruitment period and attend a total of 5 study visits: visit 1 (baseline, day 0), visit 2 (day 1 ), visit 3 (week 1 ), visit 4 (week 5 ), and visit 5 (endline, week 12) as shown in table 1. At baseline, research staff will administer questionnaires to collect sociodemographic and health data, including information on factors that confound haematological and gastrointestinal indicators, as well as take anthropometric measurements. Women will be provided with a flocked rectal swab and a container for stool sample collection. They will be asked to provide both samples to be collected on visit 2. Stool samples may be collected within 7 days of baseline if the sample is unable to be collected on the scheduled visit 2 , that is, if the woman is unable to pass stool or travels. Women will also be instructed to fast overnight prior to visit 2 .

Phlebotomists will collect a morning fasting blood sample on day 1 and at week 12 in the village at a central location. The flocked rectal swab and stool sample container will be collected. Village chiefs and village health volunteers will assist with the mobilisation of women during screening and for study visits. Venous blood will be collected in a $6 \mathrm{~mL}$ trace element-free tube, a $6 \mathrm{~mL}$ evacuated tube containing EDTA, and a $2 \mathrm{~mL}$ tube containing EDTA (Becton Dickinson). Blood, flocked rectal swabs and stool sample containers will be placed in racks in a covered icebox and transported within 2-4hours of collection to the National Institute of Public Health Laboratory for processing.

On the collection of baseline blood, flocked rectal swabs and stool sample containers, women will receive one of the three interventions $(n=160$ in each group) in which they were randomised to. Research officers will provide women with one child-safe screw cap bottle containing 88 capsules after baseline blood collection. Capsule counts will be conducted at week 1 , week 5 and week 12 to monitor adherence. Reminders and follow-up visits will be used to promote adherence and remind women to take capsules. The women will be instructed to take the supplements daily in the evening with adequate food and water in their home. The supplements will be in the form of 
tablets, labelled with a serial number and coloured sticker identifying the treatment, which will be double-blind, not known by the participant nor the study personnel. Research officers will record reported side effects, as large doses of iron may cause gastrointestinal discomfort, review the symptoms diary and encourage continued adherence. Additional home visits or phone calls will take place on an as-needed basis to ensure participants feel comfortable with the treatment, have their questions answered promptly, and all side effects documented.

Following the completion of the 12-week study, nutrition education will be provided in small groups to all women, regardless of intervention arm, by trained research staff on information about good dietary sources of iron, and practices to prevent anaemia.
Participant and public involvement in research

This research is being conducted in collaboration with the Cambodian Ministry of Health, the Provincial Health Department and Health Operational District in Kampong Thom province. Participants and the public were not involved in the research design or reporting but will be involved in research dissemination (village meetings open to participants and the community to share study findings).

\section{Laboratory methods and analyses}

A complete blood count will be performed using an automated haematology analyzer (Sysmex XN-1000, Sysmex, Kobe, Japan) to measure haemoglobin (g/L), MCV (fL), $\mathrm{MCH}(\mathrm{pg})$, RDW (\% of RBC) and reticulocyte count (\% of RBC).

Plasma, buffy coat and serum will be stored in $2 \mathrm{~mL}$ cryovials at $-80^{\circ} \mathrm{C}$ until shipment on dry ice to Canada

\section{Protocol for Lab Blood Collection}

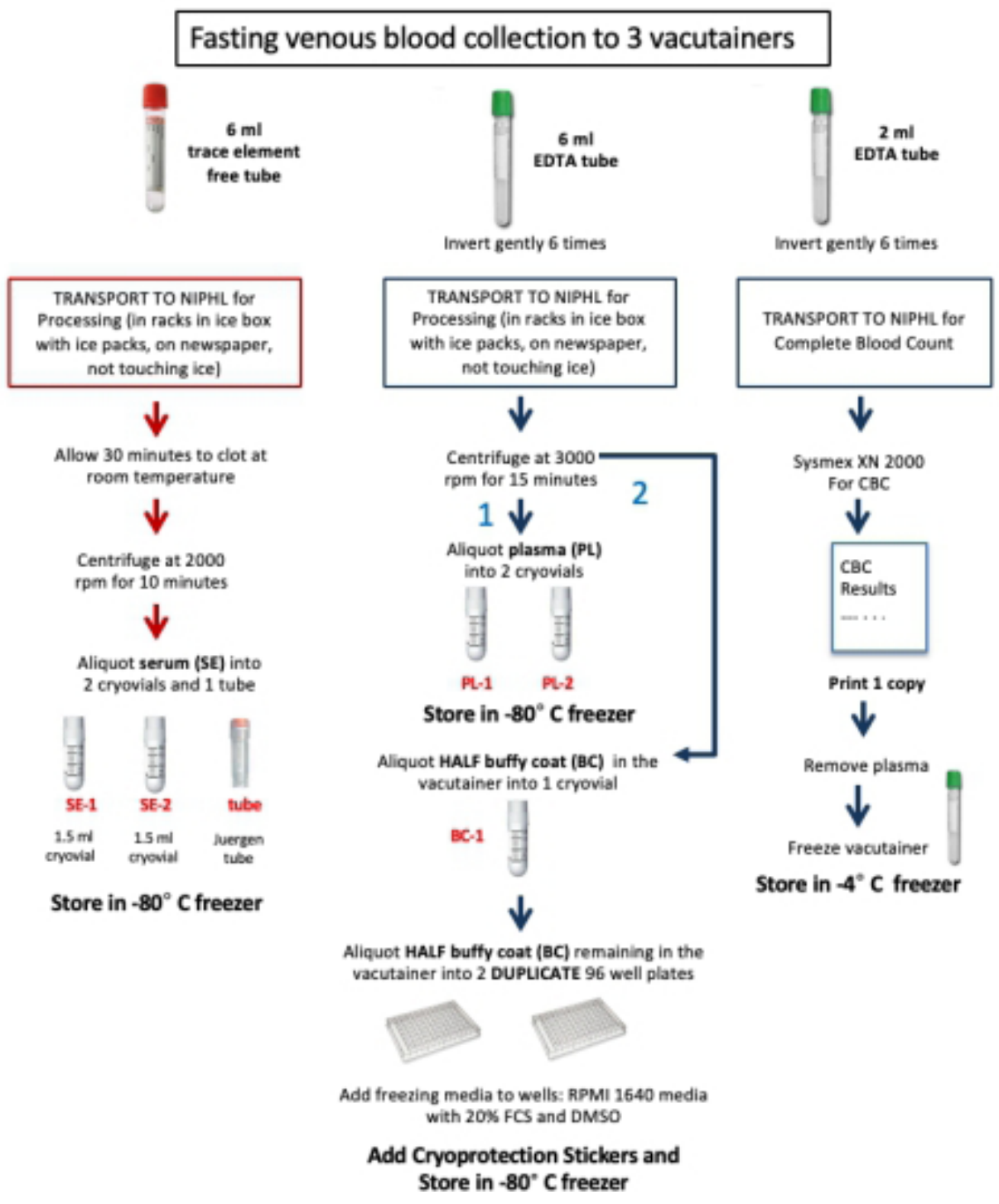

Figure 3 Blood collection protocol. 
for analysis or shipment to other institutions (figure 3). The serum will be assessed for the following indicators by using a sandwich ELISA $^{57}$ : ferritin $(\mu \mathrm{g} / \mathrm{L})$, soluble transferrin receptor $(\mathrm{sTfR})(\mathrm{mg} / \mathrm{L})$, AGP $(\mathrm{g} / \mathrm{L})$, CRP $(\mathrm{mg} / \mathrm{L})$ and retinol-binding protein $(\mu \mathrm{mol} / \mathrm{L})$. Ferritin will be adjusted for inflammation, with the use of correction factors by Namaste $e t a l$, using AGP and CRP values. ${ }^{53}$ Vitamin $\mathrm{B}_{12}(\mathrm{pmol} / \mathrm{L})$ will also be measured using an Abbott AxSym auto-analyzer with appropriate controls. Serum folate $(\mathrm{nmol} / \mathrm{L})$ will be measured with a 96-well plate microbiological assay using chloramphenicolresistant Lactobacillus rhamnosus. ${ }^{58}$ Serum hepcidin (nmol/L) will be measured using a Hepcidin-25 bioactive immunoassay kit (DRG International, Springfield, New Jersey, USA) ${ }^{59}$ Capillary haemoglobin electrophoresis will be conducted using a Sebia MINICAP analyser (Haemoglobin E programme) to detect haemoglobinopathies, including normal haemoglobin ( $\mathrm{Hb} \mathrm{A}, \mathrm{A}_{2}$ and $\mathrm{F}$ ), haemoglobin variants $(\mathrm{Hb} \mathrm{E}, \mathrm{H}$ and $\mathrm{CS}$ ) and $\alpha$-thalassemia. ${ }^{60}$ DNA will be extracted from buffy coat using a QiaAmp Blood DNA kit (Qiagen), and a multiplex PCR assay will be used to assess for common $\alpha$-globin gene deletions $\left(\alpha-^{3.7}\right.$ and $\left.\alpha-^{4.2}\right)$.

Faecal calprotectin will be measured from fresh stool using the CALEX Cap extraction device (Copan Italia SpA, Brescia, Italy) ${ }^{61}$ Fresh stool, the extracted sample and flocked rectal swab will be stored at $-20^{\circ} \mathrm{C}$ until shipment on dry ice to Canada for analysis. BÜHLMANN fCAL ELISA (BÜHLMANN Laboratories AG, Schönenbuch, Switzerland) will be used, to selectively measure calprotectin in stool extracts by sandwich ELISA.

Real-time PCR nucleic acid amplification assay will be conducted on flocked rectal swabs. ${ }^{62}$ The BD MAX enteric panel (BD Diagnostic Systems, Quebec, Canada) will target enteropathogens ${ }^{63}$ : Salmonella spp, Campylobacter spp, Shigella spp, enteroinvasive E. coli, Yersinia enterocolitica, enterotoxigenic E. coli (ETEC), Plesiomonas shigelloides and Vibrio (V. vulnuficus, V. parahaemolyticus and $V$. cholerae), and the enteric parasite panel will target: Giardia lamblia, Cryptosporidium spp (C. parvum and C. hominis) and Entamoeba histolytica. ${ }^{64}$

DNA damage will be assessed by measuring DNA singlestrand breaks, indicated by olive tail movement with use of alkali single-cell gel electrophoresis (Comet assay). ${ }^{65}$

In a subset of 150 women from our trial (50 from each trial arm), whole metagenome shotgun $16 \mathrm{~S}$ ribosomal RNA sequencing will be conducted on faecal samples, to examine the bacterial community profile differences in each arm of the study. ${ }^{66}$

\section{Participant remuneration}

All participants will be given an appropriate participation compensation at each sample collection point (baseline and endline), such as a sarong and fish sauce.

\section{Study management and monitoring}

A site supervisor will review all data collection forms on a weekly basis for completeness and protocol deviations or violations before sending them to the data management centre at HKI.

All electronic data files and hard copies of data, consent forms, questionnaires and other papers containing data will be kept in a secure place that will remain locked in the research office in the Kampong Thom health centre. CDK, HK and JF will have access to the database during the data collection period, and all co-investigators will have access to the data at all stages of data analyses and interpretation.

Data monitoring will be performed by research coordinators throughout study recruitment and participant follow-up. An independent data safety monitoring committee has not been established for this short study due to its minimal risk for human health and iron supplementation at doses less than, or equal to, the current WHO-recommended dose. However, any adverse effects will be registered, and the elected trial safety officer and Principal Investigator will be notified.

\section{Data analyses plan}

The primary outcome analysis will be a between-iron group non-inferiority comparison of mean serum ferritin at 12 weeks with the use of a generalised linear mixedeffects model, controlling for baseline ferritin (fixed effects) and health centre clusters (random effects), assigning a margin of $20 \mu \mathrm{g} / \mathrm{L}$ to define non-inferiority. ${ }^{56}$ The primary analyses will be performed on an intention to treat' basis, where all participants will be analysed according to their allocated treatment group, regardless of supplementation protocol compliance. A secondary 'per-protocol' analysis will be performed on a subset of women who consumed $\geq 80 \%$ of capsules over the study period. For the outcome measures of potential risk, faecal calprotectin concentrations and quantities of selected enteropathogens in the three groups at 12 weeks, a generalised linear model will be used, controlling for baseline values and confounding variables. Interindividual variation in DNA strand breaks and gut pathogen abundance will be minimised by using each woman as her own control, through a paired-analysis approach. We also plan to test for an interaction effect to see if outcomes differ by a woman's baseline iron status (iron-replete (ferritin $>15 \mu \mathrm{g} / \mathrm{L}$ ) or iron-deplete (ferritin $<15 \mu \mathrm{g} / \mathrm{L}$ )) or by the presence or absence of a genetic haemoglobinopathy.

All statistical analyses will be performed using Stata V.16 (StataCorp, College Station, USA), and a p value of 0.05 will indicate statistical significance.

\section{ETHICS AND DISSEMINATION \\ Ethical considerations}

Participants will provide signed informed consent (online supplementary file) before participating in the study. Participants will be able to withdraw from the study at any point with no reason needing to be given. Ethics approval has been granted by the University of British Columbia Clinical Research Ethics Board (H18-02610), 
the Children's and Women's Health Centre of British Columbia Research Ethics Board (H18-02610) and the National Ethics Committee for Health Research in Phnom Penh (273-NECHR). This trial was registered in ClinicalTrials.gov in July 2019. The trial is being conducted in accordance with the ethical principles of the Declaration of Helsinki, international law and Good Clinical Practice guidelines.

\section{Dissemination plan}

The research group plans to achieve extensive dissemination of trial results to ensure widespread visibility of findings. We will be sharing our research throughout all stages of the project through collaborative efforts to engage all stakeholders, partners and knowledge users such as at the monthly Cambodian Nutrition Working Group meetings, where researchers and non-governmental organisations involved in nutrition research and meet together. The main results from this study will be disseminated through at least one publication, and others with secondary results are planned, in open access peer-reviewed journals. In addition, a dialogue will be initiated with key nutrition stakeholders, and results will be presented at relevant conferences, symposia and through social networks and other media channels in Canada, Cambodia and internationally. The results from this trial will be reported at the completion of the study in accordance with the Consolidation of Standards for Reporting Trials guidelines. After data analyses, we will return to the study health centres to share the study's findings. Any women found to have iron deficiency will receive a 3 month supply of iron supplements at the end of the trial, regardless of intervention arm.

\section{Author affiliations}

${ }^{1}$ Department of Food, Nutrition and Health, The University of British Columbia, Vancouver, British Columbia, Canada

${ }^{2}$ Healthy Starts, British Columbia Children's Hospital Research Institute, Vancouver, British Columbia, Canada

${ }^{3}$ Department of Pathology and Laboratory Medicine, University of British Columbia, Vancouver, British Columbia, Canada

${ }^{4}$ Department of Biostatistics, Women's Health Research Institute, Vancouver, British Columbia, Canada

${ }^{5}$ School of Population and Public Health, The University of British Columbia, Vancouver, British Columbia, Canada

${ }^{6}$ Helen Keller International Cambodia, Phnom Penh, British Columbia, Cambodia

Contributors JF, DMG, RE, HK and CDK contributed to the conception and design of the trial protocol. AA provided advice on the sample size calculation and statistical analysis plan. JF and CDK drafted the protocol manuscript, and all authors contributed to review and revision in the final stages and approved the final manuscript. JF and HK coordinated and led the field activities in Cambodia. LXP supported field activities in Cambodia. CDK is responsible for the overall coordination and supervision of the project.

Funding This project is funded by the Canadian Institutes of Health Research (CIHR) Project Grant (ID400771). The nutritional supplements were provided in kind by The Factors Group of Companies (Coquitlam, Canada). FecalSwab were provided in kind by Copan Italia SpA (Brescia, Italy).

Disclaimer The funders had no role in study design and will not have any role during collection, analyses, interpretation of the data, or decision to submit the results for publication.

Competing interests None declared.
Patient and public involvement Patients and/or the public were involved in the design, or conduct, or reporting, or dissemination plans of this research. Refer to the Methods section for further details.

Patient consent for publication Obtained.

Provenance and peer review Not commissioned; externally peer reviewed.

Open access This is an open access article distributed in accordance with the Creative Commons Attribution Non Commercial (CC BY-NC 4.0) license, which permits others to distribute, remix, adapt, build upon this work non-commercially, and license their derivative works on different terms, provided the original work is properly cited, appropriate credit is given, any changes made indicated, and the use is non-commercial. See: http://creativecommons.org/licenses/by-nc/4.0/.

ORCID iD

Jordie AJ Fischer http://orcid.org/0000-0003-1268-5564

\section{REFERENCES}

1 Guideline. Daily iron supplementation in infants and children. Geneva: World Health Organization, 2016.

2 MSY L, Speedy J, Styles CE, et al. Daily iron supplementation for improving anaemia, iron status and health in menstruating women (review). Cochrane Database Syst Rev 2016;4.

3 Karakochuk CD. Iron supplementation in predominantly ironreplete populations: is there an emerging concern? . Sight and Life Magazine, 2016: 30. 47-54.

4 Merrill RD, Shamim AA, Ali $\mathrm{H}$, et al. High prevalence of anemia with lack of iron deficiency among women in rural Bangladesh: a role for thalassemia and iron in groundwater. Asia Pac J Clin Nutr 2012;21:416-24.

5 Karakochuk CD, Whitfield KC, Barr SI, et al. Genetic hemoglobin disorders rather than iron deficiency are a major predictor of hemoglobin concentration in women of reproductive age in rural prey Veng, Cambodia. J Nutr 2015;145:134-42.

6 Wieringa FT, Sophonneary P, Whitney S, et al. Low prevalence of iron and vitamin A deficiency among Cambodian women of reproductive age. Nutrients 2016;8:197.

7 Measure DHS. Demographic and health survey 2014: key indicators report. Phnom Penh, 2015.

8 Harvey-Leeson S, Karakochuk CD, Hawes M, et al. Anemia and micronutrient status of women of childbearing age and children 6-59 months in the Democratic Republic of the Congo. Nutrients 2016;8:98..

9 Chandyo RK, Henjum S, Ulak M, et al. The prevalence of anemia and iron deficiency is more common in breastfed infants than their mothers in Bhaktapur, Nepal. Eur J Clin Nutr 2016;70:456-62.

10 Wirth JP, Rohner F, Woodruff BA, et al. Anemia, micronutrient deficiencies, and malaria in children and women in Sierra Leone prior to the Ebola outbreak - Findings of a cross-sectional study. PLoS One 2016;11:e0155031.

11 Nguyen PH, Gonzalez-Casanova I, Nguyen H, et al. Multicausal etiology of anemia among women of reproductive age in Vietnam. Eur J Clin Nutr 2015;69:107-13.

12 Fang Y-Z, Yang S, Wu G. Free radicals, antioxidants, and nutrition. Nutrition 2002;18:872-9.

13 Jaeggi T, Kortman GAM, Moretti D, et al. Iron fortification adversely affects the gut microbiome, increases pathogen abundance and induces intestinal inflammation in Kenyan infants. Gut 2015;64:731-42.

14 Schümann K, Ettle T, Szegner B, et al. On risks and benefits of iron supplementation recommendations for iron intake revisited. J Trace Elem Med Biol 2007;21:147-68.

15 Schümann K, Kroll S, Weiss G, et al. Monitoring of hematological, inflammatory and oxidative reactions to acute oral iron exposure in human volunteers: preliminary screening for selection of potentiallyresponsive biomarkers. Toxicology 2005;212:10-23.

16 Brissot P, Ropert M, Le Lan C, et al. Non-Transferrin bound iron: a key role in iron overload and iron toxicity. Biochim Biophys Acta 2012;1820:403-10.

17 Aksu BY, Hasbal C, Himmetoglu S, et al. Leukocyte DNA damage in children with iron deficiency anemia: effect of iron supplementation. Eur J Pediatr 2010;169:951-6.

18 Mollet IG, Patel D, Govani FS, et al. Low dose iron treatments induce a DNA damage response in human endothelial cells within minutes. PLoS One 2016;11:e0147990.

19 Li K, Reichmann H. Role of iron in neurodegenerative diseases. J Neural Transm 2016;123:389-99. 
20 Hansen JB, Moen IW, Mandrup-Poulsen T. Iron: the hard player in diabetes pathophysiology. Acta Physiol 2014;210:717-32.

21 Swaminathan S, Fonseca VA, Alam MG, et al. The role of iron in diabetes and its complications. Diabetes Care 2007;30:1926-33.

22 Lind T, Seswandhana R, Persson L-A, et al. Iron supplementation of iron-replete Indonesian infants is associated with reduced weight-forage. Acta Paediatr 2008;97:770-5.

23 Dewey KG, Domellöf M, Cohen RJ, et al. Iron supplementation affects growth and morbidity of breast-fed infants: results of a randomized trial in Sweden and Honduras. J Nutr 2002;132:3249-55.

24 Walter T, Pino P, Pizarro F, et al. Prevention of iron-deficiency anemia: comparison of high- and low-iron formulas in term healthy infants after six months of life. J Pediatr 1998;132:635-40.

25 Lozoff B. Iron deficiency and child development. Food Nutr Bull 2007;28:S560-71.

26 Lozoff B, Castillo M, Clark KM, et al. Iron-Fortified vs low-iron infant formula: developmental outcome at 10 years. Arch Pediatr Adolesc Med 2012;166:208-15.

27 Soofi S, Cousens S, lqbal SP, et al. Effect of provision of daily zinc and iron with several micronutrients on growth and morbidity among young children in Pakistan: a cluster-randomised trial. Lancet 2013;382:29-40.

28 Sazawal S, Black RE, Ramsan M, et al. Effects of routine prophylactic supplementation with iron and folic acid on admission to hospital and mortality in preschool children in a high malaria transmission setting: community-based, randomised, placebo-controlled trial. Lancet 2006;367:133-43.

29 Pasricha S-R, Hayes E, Kalumba K, et al. Effect of daily iron supplementation on health in children aged 4-23 months: a systematic review and meta-analysis of randomised controlled trials. Lancet Glob Health 2013;1:e77-86.

30 Stoltzfus RJ. Iron-Deficiency anemia: reexamining the nature and magnitude of the public health problem. J Nutr2001;131:697S--700.

31 Paganini D, Uyoga MA, Kortman GAM, et al. Prebiotic galactooligosaccharides mitigate the adverse effects of iron fortification on the gut microbiome: a randomised controlled study in Kenyan infants. Gut 2017;66:1956-67.

32 Paganini D, Zimmermann MB. The effects of iron fortification and supplementation on the gut microbiome and diarrhea in infants and children: a review. Am J Clin Nutr 2017;106:1688S-93.

33 National Institute of Statistics, Directorate General for Health, and ICF International, 2015. Cambodia demographic and health survey. Phnom Penh, Cambodia, and Rockville, Maryland, USA: National Institute of Statistics, Directorate General for Health, and ICF International, 2014.

34 Karakochuk CD, Barker MK, Whitfield KC, et al. The effect of oral iron with or without multiple micronutrients on hemoglobin concentration and hemoglobin response among nonpregnant Cambodian women of reproductive age: a $2 \times 2$ factorial, double-blind, randomized controlled supplementation trial. Am J Clin Nutr 2017;106:233-44.

35 Zimmermann MB, Fucharoen S, Winichagoon P, et al. Iron metabolism in heterozygotes for hemoglobin $E(\mathrm{HbE})$, alphathalassemia 1, or beta-thalassemia and in compound heterozygotes for HbE/beta-thalassemia. Am J Clin Nutr 2008;88:1026-31.

36 Andrews SC, Robinson AK, Rodríguez-Quiñones F. Bacterial iron homeostasis. FEMS Microbiol Rev 2003:27:215-37.

37 Dostal A, Fehlbaum S, Chassard C, et al. Low iron availability in continuous in vitro colonic fermentations induces strong dysbiosis of the child gut microbial consortium and a decrease in main metabolites. FEMS Microbiol Ecol 2013;83:161-75.

38 Lönnerdal B. Excess iron intake as a factor in growth, infections, and development of infants and young children. Am J Clin Nutr 2017; $106: 1681$ S-7

39 Kortman GAM, Raffatellu M, Swinkels DW, et al. Nutritional iron turned inside out: intestinal stress from a gut microbial perspective. FEMS Microbiol Rev 2014;38:1202-34.

40 Bullen J, Griffiths E, Rogers H, et al. Sepsis: the critical role of iron. Microbes Infect 2000;2:409-15.

41 Anderson RC, Cookson AL, McNabb WC, et al. Lactobacillus plantarum DSM 2648 is a potential probiotic that enhances intestinal barrier function. FEMS Microbiol Lett 2010;309:no-92.

42 Weinberg ED. The Lactobacillus anomaly: total iron abstinence. Perspect Biol Med 1997;40:578-83.

43 Zeng MY, Inohara N, Nuñez G. Mechanisms of inflammation-driven bacterial dysbiosis in the gut. Mucosal Immunol 2017;10:18-26.
44 Tondeur MC, Schauer CS, Christofides AL, et al. Determination of iron absorption from intrinsically labeled microencapsulated ferrous fumarate (sprinkles) in infants with different iron and hematologic status by using a dual-stable-isotope method. Am J Clin Nutr 2004;80:1436-44.

45 Kortman GAM, Boleij A, Swinkels DW, et al. Iron availability increases the pathogenic potential of Salmonella typhimurium and other enteric pathogens at the intestinal epithelial interface. PLoS One 2012;7:e29968.

46 Hallberg L, Ryttinger L, Sölvell L. Side-Effects of oral iron therapy. A double-blind study of different iron compounds in tablet form. Acta Med Scand Supp/ 1966;459:3-10.

47 Pineda O, Ashmead HD. Effectiveness of treatment of iron-deficiency anemia in infants and young children with ferrous bis-glycinate chelate. Nutrition 2001:17:381-4.

48 Bovell-Benjamin AC, Viteri FE, Allen LH. Iron absorption from ferrous bisglycinate and ferric trisglycinate in whole maize is regulated by iron status. Am J Clin Nutr 2000;71:1563-9.

49 Duque X, Martinez H, Vilchis-Gil J, et al. Effect of supplementation with ferrous sulfate or iron bis-glycinate chelate on ferritin concentration in Mexican schoolchildren: a randomized controlled trial. Nutr J 2014;13:71.

50 Bagna R, Spada E, Mazzone R, et al. Iron supplementation with iron sulfate versus iron bisglycinate chelate in preterm newborns. Curr Pediatr Rev 2018;14:123-9.

51 Ferrari P, Nicolini A, Manca ML, et al. Treatment of mild nonchemotherapy-induced iron deficiency anemia in cancer patients: comparison between oral ferrous bisglycinate chelate and ferrous sulfate. Biomed Pharmacother 2012;66:414-8.

52 Zimmermann MB, Chassard C, Rohner F, et al. The effects of iron fortification on the gut microbiota in African children: a randomized controlled trial in Cote d'Ivoire. Am J Clin Nutr 2010;92:1406-15.

53 Namaste SMI, Rohner F, Huang J, et al. Adjusting ferritin concentrations for inflammation: biomarkers reflecting inflammation and nutritional determinants of anemia (BRINDA) project. Am J Clin Nutr 2017.

54 Daru J, Allotey J, Peña-Rosas JP, et al. Serum ferritin thresholds for the diagnosis of iron deficiency in pregnancy: a systematic review. Transfus Med 2017;27:167-74.

55 WHO. Guideline on use of ferritin concentrations to assess iron status in individuals and populations. Geneva: World Health Organization, 2020.

56 WHO. Assessing the iron status of populations. 2nd ed. Geneva: World Health Organization, 2007.

57 Erhardt JG, Estes JE, Pfeiffer CM, et al. Combined measurement of ferritin, soluble transferrin receptor, retinol binding protein, and C-reactive protein by an inexpensive, sensitive, and simple sandwich enzyme-linked immunosorbent assay technique. J Nutr 2004;134:3127-32.

58 O'Broin S, Kelleher B. Microbiological assay on microtitre plates of folate in serum and red cells. J Clin Pathol 1992;45:344-7.

59 Ganz T, Olbina G, Girelli D, et al. Immunoassay for human serum hepcidin. Blood 2008;112:4292-7.

60 Giordano PC. Carrier diagnostics and prevention of hemoglobinopathies using capillary electrophoresis. 1St. France: Sebia, 2007.

61 BÜHLMANN fCal ELISA Calprotectin. BÜHLMANN laboratories, 2018. Available: https://www.buhlmannlabs.ch/wp-content/uploads/ 2015/01/EK-CAL_-IFU_CE_2018-04-10.pdf [Accessed Jan 2019].

62 Enteric Solutions. Bd molecular diagnostics, 2018. Available: http://moleculardiagnostics.bd. com/syndromic-solutions/entericsolutions/ [Accessed Jan 2019].

63 DeBurger B, Hanna S, Powell EA, et al. Utilizing BD MAX'M enteric bacterial panel to detect stool pathogens from rectal swabs. $B M C$ Clin Pathol 2017;17:7.

64 Madison-Antenucci S, Relich RF, Doyle L, et al. Multicenter evaluation of BD max enteric parasite real-time PCR assay for detection of Giardia duodenalis, Cryptosporidium hominis, Cryptosporidium parvum, and Entamoeba histolytica. J Clin Microbiol 2016;54:2681-8.

65 Singh NP, McCoy MT, Tice RR, et al. A simple technique for quantitation of low levels of DNA damage in individual cells. Exp Cell Res 1988;175:184-91.

66 Vincent C, Miller MA, Edens TJ, et al. Bloom and bust: intestinal microbiota dynamics in response to hospital exposures and Clostridium difficile colonization or infection. Microbiome 2016;4:12. 